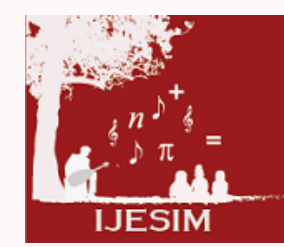

International Journal of Educational Studies in Mathematics

ISSN: 2148-5984

wWw.ijesim.com

\title{
The Effect of Conceptual Change Texts on Understanding of Height Concept of Secondary School $5^{\text {th }}$ Class Students
}

\author{
Nejla Gürefe ${ }^{1}$, Saliha Hilal Yarar ${ }^{1}$, Büsra Nur Pazarbasi' ${ }^{1}, H_{a s a n}$ Es $^{1}$
}

${ }^{1}$ Gazi University, Gazi Educational Faculty, Department of Mathematical Education, Turkey

\section{ABSTRACT}

\begin{abstract}
It is important to be provided meaningful and permanent learning in the Secondary School Mathematics Curriculum based constructivist approach. In order to achieve it, firstly, existing information of students about a subject should be determined and lastly, if they have misconceptions related this subject, these misconceptions are determined and removed. One of the effective methods using to determine is Conceptual Change Texts (CCT). The purpose of this study was to provide being learnt "Height" concept by the secondary school fifth class students and to remove misconceptions of these students with CCT. The study was made of the spring semester of the 2012-2013 academic years. Participants were 80 students from two different schools of Ankara. One of these schools was public schools and the other school was private school. A quasi-experimental design was used as the research method. There were two groups being experimental and control in each of schools. CCT was used in the experimental group and traditional instruction was used in the control group. "Height Achievement Test" developed by researchers was applied as pre-test and post-test for the experimental and control group. Difference between scores of experimental group and control groups was analyzed with independent samples t-test. The findings in this study indicated that there was a significant difference between the control and experimental groups in favour of experimental group ( $\mathrm{p}<.05)$ for the both schools. Findings indicated that lessons being studied with conceptual change texts are more effective than traditional instruction.
\end{abstract}

Keywords:

Conceptual change text, height concept, geometry.

(C) 2014 IJESIM. All rights reserved

Article History:

Received 27.02.2014 Received in revised form 11.04.2014 Accepted 16.05.2014 Available online 01.06.2014

\section{Extended Summary}

\section{Purpose}

It is important that students have previously acquired knowledge during learning process new concept. If previous knowledge is missing or incorrect, new knowledge which students gain is incorrect. Incorrect prior knowledge can make learning difficult. Because of this, knowledge which students have previously must be reviewed and according to this case, training must be organized (Hewson, 1984).

Misunderstanding of the concepts and the creation of erroneous concepts are known as misconception. Misconception is an important problem which students have in mathematics lessons, especially in geometry. Because geometry is abstract, students have difficulty during learning concepts of geometry. Unfortunately, in our country, level of students' understanding geometry is lower than the level of understanding algebra (Yenilmez and Yaşa, 2008). "Height" concept is one of geometric concepts which students learn difficulty. Because "height" concept is used in a lot of area in geometry such as area and volume calculations, it is

\footnotetext{
${ }^{1}$ Corresponding author's address: Gazi University, Gazi Educational Faculty, Department of Mathematical Education,Turkey

Telephone: +903122023697

Fax:

e-mail: ncalik@gazi.edu.tr

http://dx.doi.org/10.17278/ijesim.2014.01.005
} 
important which students learn correctly this (Van De Walle, 1998). Because of this, students' misconceptions must be detected and these misconceptions must be removed. Conceptual Change Texts (CCT) are a one of the methods which provide this (Alvermannan \& Hague, 1989).

In this study, following problems is researched;

1) For public school students,

a) Is there a significant difference between pre-tests scores of control group students and experimental group students?

b) Is there a significant difference between pre-test scores of experimental group students and post-test scores of experimental group students?

c) Is there a significant difference between pre-test scores of control group students and post- test scores of control group students?

d) Is there a significant difference between post-tests scores of control group students and experimental group students?

2) For private school students,

a) Is there a significant difference between pre-tests scores of control group students and experimental group students?

b) Is there a significant difference between pre-test scores of experimental group students and post-test scores of experimental group students?

c) Is there a significant difference between pre-test scores of control group students and post-test scores of control group students?

d) Is there a significant difference between post-tests scores of control group students and experimental group students?

\section{Method}

In this study, the quasi-experimental design was used. The research sample consisted of 80 students enrolled in 5th Class from public and private secondary schools in Ankara, during the 2012-2013 spring semester of academic year. 46 students were selected from public schools and34 students were selected from private school. One control group and one experimental group classes were identified in both public and private schools. The traditional method was used in the control groups and a teaching based on the CCT was used in the experimental groups. The data was collected through "Height Achievement Test" and CCT formed by the researcher. Height Achievement Test consists of six sections and has 100 points. The test is developed to detect misconceptions of students and to learn what they know about "height" concept. The questions in this test were detected by scanning literature. It was wanted from students to answer an openended question in the first section, to explain true or false statements with the reasons in the second section, to answer as correct a multiple-choice question in the third section, to identify heights of the triangles and quadrilaterals located in a variety of ways in the fourth section, to detect segments given on polygons which height is in the fifth sections, to draw heights belong to edge which marked on polygons in the sixth sections of texts.

CCT was prepared by considering four process. These process are inability, intelligibility, rationality and efficiency. These texts was prepared to change wrong perceptions of students, to provide permanent learning, to provide better understanding of "height" concept by the students.

Independent samples t-test and paired samples t- test were used for analyzing the data. Independent samples t- test was used whether experimental groups' and control groups' scores differ significantly in terms of success. Paired samples t-test was used whether experimental groups' scores differ significantly in terms of success and control groups' scores differ significantly in terms of success.

\section{Results}

In this study, CCT was used to detect having students' misconceptions about concept of height and to provide better understanding of height concept by the students. 
As a result of this study, pre-test scores of the experimental and control groups students in both public and private schools did not differ significantly $(p>.05)$. However, post-test scores of experimental and control groups for the both schools differ significantly in favor of the experimental group $(p<.05)$. In addition, there is no statistically significant differences between pre-test scores and post-test scores of students in control groups of both schools $(p>.05)$.

Looking at the results, the students of experimental groups was seen more successful than the students of control groups for both schools. This situation shows that teaching with CCT is an useful method for teaching a subject in mathematics.

\section{Discussion}

Learning is a comprehensive process that has several methods and techniques. In this process, the usage of methods and techniques in the right place at the right time are so important. Many similar studies show that traditional methods do not raise student achievement on desired levels. A learning environment which students discover concepts and construct knowledge themselves must be prepared for the students. However, the role of teachers must guide instead of leadership. CCT can be considered as a method that can support this process.

Mathematics and geometry have a lot of concepts and knowledge. These concepts and knowledge must be required to grasp the students well as in relation to each other for the creation of meaningful learning in individuals. This study shows that CCT contributes creation of knowledge as meaningful. Guzzetti et all (1992) support our study. 


\title{
Ortaokul 5. Sınıf öğrencilerinin yükseklik kavramını anlamalarında kavramsal değişim metinlerinin etkisi
}

\author{
Nejla Gürefe ${ }^{1}$, Saliha Hilal Yarar ${ }^{1}$, Büşra Nur Pazarbaşi ${ }^{1}$ ve Hasan Es ${ }^{1}$
}

${ }^{1}$ Gazi Üniversitesi, Gazi Ĕ̆itim Fakültesi, Matematik Eğitimi Anabilim Dal, Türkiye

ÖZ

\begin{abstract}
İlköğretim Matematik Öğretim Programının temel aldığı yapılandırmacı öğrenme yaklaşımı, anlamlı öğrenmenin gerçekleşmesi için mevcut bilgilerin önemli olduğunu savunmaktadır. Bu nedenle öğretim sürecine başlamadan önce öğrencilerin kavram yanılgılarının belirlenmesi ve giderilmesi gerekmektedir. Bu çalışmanın amacı, Kavramsal Değişim Metinlerinin (KDM) ortaokulda öğrenim gören öğrencilerin geometride yer alan Yükseklik kavramını öğrenmeleri ve bu kavrama yönelik kavram yanılgılarının giderilmesi üzerindeki etkisini incelemektir. Bu çalışmanın örneklemini, Ankara'nın bir devlet ve bir de özel okulu olmak üzere iki ortaokulunun 5. sinıfında öğrenim gören 80 öğrenci oluşturmaktadır. Bu çalışma için her iki okuldan da derslerde kavramsal değişim metinlerinin uygulandığı deney grubu ve Milli Eğitim müfredatı tarafından önerilen yöntemin uygulandığı kontrol grubu olarak ikişer sınıf belirlenmiştir. Çalışma, 2012-2013 eğitim-öğretim yılının bahar döneminde yapılmış ve çalışmada yarı-yapılandırılmış deneysel desen kullanılmıştır. Araştırmacılar tarafından geliştirilen Yükseklik Kavramı Başarı Testi (YKBT) deney ve kontrol grubuna ön test-son test olarak uygulanmıştır. Bu araştırmanın bulgularına göre kavramın öğrenilmesinde başarı açısından deney grubu lehine anlamlı bir farklılık bulunmuştur.
\end{abstract}

Anahtar Kelimeler:

Kavramsal değişim metni, yükseklik kavramı, geometri

(C) 2014 IJESIM. Tüm hakları saklıdır.

Makale Tarihçesi:

Alındı 27.02.2014 Düzeltilmiş hali alındı 11.04.2014 Kabul edildi 16.05.2014 Çevrimiçi yayınlandı 01.06.2014

\section{Giriş}

Matematik eğitim ve öğretimi, bilimsel hayatın gelişmesine ve bu sayede insan yaşamına olan katkısından dolayı önemlidir (Altun, 2010). Bilim ve teknolojinin de hızlı gelişimiyle birlikte son yıllarda matematik eğitim ve öğretiminde önemli değişiklikler ve yenilikler meydana gelmiştir. Meydana gelen bu yeni anlayış ile öğrenci bilgiyi hazır olarak alan konumdan çıkarılarak, bilgiye öğretmenin de rehberliğinde kendisinde var olan ön bilgileri yeniden düzenleyerek ulaşabilen bir konuma gelmiştir. Bu yaklaşım yapılandırmacılık olarak isimlendirilmektedir. Hand, Tregaust ve Vance' ye (1997) göre yapılandırmacı yaklaşım, temelde Piaget' in zihinsel psikolojisi, Ausubel' in anlamlı öğrenme, Bruner' in araştırma, Posner ve arkadaşlarının kavramsal değişim, Johnson'un sosyal etkileşim teorilerine dayanmaktadır (Akt: Köseoğlu ve Kavak, 2001). Ausubel (1968) açık, net ve iyi düzenlenmiş bir bilişsel yapının öğrenmeyi ve yeni bilgiyi zihinde tutmayı kolaylaştıracağını, bu nedenle öğrenme sürecinde öğrenende var olan bilgilerle yeni bilgiler arasında bağlantı kurulması gerektiğini ve bu süreçte kavramların iyi organize edilmesi gerektiğini ifade etmektedir (Akt: Ivie, 1998).

Matematik öğretiminin temel ilkelerinden ilki kavramsal temellerin oluşturulmasıdır. Bu nedenle kavram öğretimi matematikte çok önemli bir yere sahiptir (Altun, 2010). Hem Ausubel' in hem de Piaget' in öğrenme anlayışlarında da kavram öğretiminin ve bu kavramların doğru bir şekilde anlamlandırılmasında bireylerin daha önce edindikleri ön öğrenmelerin oldukça önemli olduğunu görmekteyiz. Bilginin zihinde hatalı bir şemaya oturtulması yanlış, eksik ve yanılgılar içeren öğrenmeleri meydana getirmektedir. Bu nedenle öğrencilerin mevcut bilgileri gözden geçirilmeli ve tüm bunlar dikkate alınarak öğretime şekil verilmelidir. Çoğu kez bu hatalı ve eksik ön bilgiler, öğretime karşı direnç gösterip öğrenmeyi zorlaştırabilir (Hewson, 1984). Matematiksel kavramların doğru ve eksiksiz öğrenilmesi bir sonraki öğrenmeyi etkileyeceği gerekçesiyle öğrencinin zihninde hatalı kavram geliştirmemesi son derece önemlidir.

Sorumlu yazarın adresi: Gazi Üniversitesi, Gazi Eğitim Fakültesi, Matematik Eğitimi Anabilim Dalı, Türkiye

Telefon: +90 3122023697

Faks:

e-posta: ncalik@gazi.edu.tr

http://dx.doi.org/10.17278/ijesim.2014.01.005 
Sözcükleri yanlış anlama veya hatalı kavram oluşturma olarak bilinen kavram yanılgısı rastgele yapılmış bir hata değildir. Sadece bir kavramın olması gereken bilimsel tanımından farklı bir anlamda zihnimizde yer alması demektir (Yenilmez ve Yaşa, 2008). Kavram yanılgıları tüm derslerde olduğu gibi matematik öğretiminde de öğrenci ve öğretmenler için üzerinde yoğunlaşılması gereken problemli bir durumdur. Bu soruna, matematiğin önemli bir öğrenme alanı olan okul matematiğinde geniş yer tutan geometri öğretiminde de çok sık rastlanmaktadır. Öğrenciler geometrik kavramları ilk kez öğrenmeye başladıklarında, çoğu kez hayat tecrübeleri başta olmak üzere sezgi, fikir, ön yargı ve korkularını da beraberlerinde getirir. Bunlar, hatalı ve eksik öğrenmelere sebebiyet verebilirken, sonradan düzeltilmesi emek isteyen ve oldukça çaba gerektiren sorunlara neden olabilmektedir.

Maalesef ülkemizde öğrencilerimizin geometri dersini anlama düzeyi, cebiri anlama düzeyinden daha düşüktür (Yenilmez ve Yaşa, 2008). Geometrinin soyut yapısından dolayı, öğrenciler geometrik kavramları anlamakta güçlük çekerler. Anlaşılmayı kolaylaştırmak için çoğu kez günlük hayattan örnekler verilir ancak bu örnekler, bazen matematiksel anlamlarından farklı olarak öğrencilerde yanlış öğrenmelere sebep olabilir.

Ortaokul 5.sınıf müfredatında yer alan ve öğrencilerin anlamakta güçlük çektikleri ve yanlış anlama geliştirdikleri kavramlardan biri de yükseklik tir. Geometride yer alan; alan-hacim hesaplama gibi geometri konularının doğru bir şekilde kavranılmasının temelinde bu kavramının doğru olarak algılanıp algılanmama durumu vardır (Van De Walle, 1998).Bu sebeple yükseklik konusunda öğrencilerin sahip olduğu kavram yanılgılarının ortaya çıkarılması, bu yanılgıların giderilmesi ve konunun anlamlı bir şekilde kavratılması oldukça önemlidir. Yanılgıların belirlenip, ortadan kaldırılmasını sağlayan yöntemlerden biri de Kavramsal Değişim Metinleri (KDM) dir (Alvermann ve Hague, 1989).

Öğrencilerin öğretilecek konu ile ilgili sahip oldukları kavram yanılgılarının, doğru bilgilerle değiştirilmesi kavramsal değişim olarak adlandırılmaktadır (Wang ve Andre, 1991). Kavramsal değişim metinlerinde öğrencilerin sahip olduğu kavram yanılgılarını onlara hissettirebilmek için konu ile ilgili soru sorulur. Ardından o konuyla alakalı sık rastlanan veya rastlanabilecek kavram yanılgılarının neler olduğu belirtilerek, hatalı olma sebepleri açıklanır. Bu sayede öğrenciler, mevcut hatalı ön bilgilerinin yetersiz kaldığını görür. Son olarak da yeni bilgiler ve bu bilgileri içeren örnekler verilir (Pınarbaşı ve Canbolat, 2002).

Posner ve arkadaşları (1982) öğrencilerde kavramsal değişimin meydana gelebilmesi için dört şarta ihtiyaç duyulduğunu ve bu şartların aşağıdaki gibi olduğunu ifade etmektedir:

- Yetersizlik: Öğrenciler bazı olayları açıklamada mevcut bilgilerinin yetersiz olduğunu hissetmelidir.

- Anlaşılabilirlik: Öğrenciler karşılaştığı yeni kavramların ne anlam ifade ettiğini kolaylıkla anlayabilmelidir.

- Mantıklılık: Öğrenciler yeni kavramları akla yakın ya da inandırıcı bulmalıdır.

- Verimlilik: Öğrenciler öğrendikleri kavramları yeni durumlara uygulayabilmeli ve farklı durumları açılamada kullanabilmelidir (Akbaş ve Uzunöz, 2011).

Kavramsal değişim metinleri ile öğretim daha çok fen bilimleri alanında yapılan çalışmalarda karşımıza çıkmakta, matematikte ise kavram yanılgıları üzerine pek çok araştırma yapılmış olmasına rağmen bu stratejinin kullanıldığı çalışmalara pek rastlanmamaktadır. Matematikte kavram öğretimi dersin temelini oluşturduğu için, bu çalışmada $\mathrm{KDM}^{\prime}$ nin, geometrideki yükseklik kavramının daha iyi kavranılmasını sağlayıp sağlamadığı ve bu konudaki kavram yanılgılarını ortaya çıkarmada ve bu yanılgıların giderilmesinde ne kadar etkili olduğu araştırılmaya çalışılmıştır. Bu anlamda aşağıdaki problemlere cevap aranmıştır;

1) Devlet Okulunda öğrenim gören,

a) Deney ve kontrol gruplarındaki öğrencilerin ön testleri arasında anlamlı bir farklılık var mıdır?

b) Deney grubundaki öğrencilerin ön test ve son testleri arasında anlamlı bir farklılık var mıdır?

c) Kontrol grubundaki öğrencilerin ön test ve son testleri arasında anlamlı bir farklılık var mıdır?

d) Deney ve kontrol gruplarındaki öğrencilerin son testleri arasında anlamlı bir farklılık var mıdır? 
2) Özel Okulda öğrenim gören,

a) Deney ve kontrol gruplarındaki öğrencilerin ön testleri arasında anlamlı bir farklılık var mıdır?

b) Deney grubundaki öğrencilerin ön test ve son testleri arasında anlamlı bir farklılık var mıdır?

c) Kontrol grubundaki öğrencilerin ön test ve son testleri arasında anlamlı bir farklılık var mıdır?

d) Deney ve kontrol gruplarındaki öğrencilerin son testleri arasında anlamlı bir farklılık var mıdır?

\section{Yöntem}

\section{Araștırma Deseni}

$\mathrm{Bu}$ araştırmada ön-test ve son-test gruplarının yer aldığı yarı deneysel desen kullanılmıştır. Devlet ve özel okulların her ikisinden de ikişer sınıf belirlenerek sınıflardan biri kontrol grubu, diğeri ise deney grubu olarak seçilmiştir. Deney gruplarında kavramsal değişim metinlerine, kontrol gruplarında ise geleneksel yönteme dayalı bir öğretim uygulanmıştır.

\section{Çalışma Grubu}

Bu araştırmanın çalışma grubunu, 5. sınıfta öğrenim gören 80 öğrenci oluşturmaktadır. Öğrenciler Ankara'nın özel ve devlet okulu olan iki farklı ortaokulundaki dört farklı şubede eğitim almaktadır. Bu öğrencilerin $46^{\prime}$ sı devlet okulundan, $34^{\prime}$ ü ise özel okuldan seçilmiştir. Araştırmanın yürütüldüğü devlet okulunun 5. sınıflarında öğrenim gören öğrencilerden seviyelerinde homojenlik olanlar deney ve kontrol grupları olarak belirlendiği gibi özel okul için de yine aynı şekilde işlem yapılmıştır.

\section{Veri Toplama Araçları}

Bu bölümde veri toplama araçlarının geliştirilme sürecine yer verilmiştir. Çalışmada veri toplamak amacıyla araştırmacılar tarafından geliştirilen Yükseklik Başarı Testi (YBT) ve Kavramsal Değişim Metinleri (KDM) kullanılmıştır.

Yükseklik başarı testi (YBT): Veri toplama aracı olarak, çalışmaya katılan 5. sınıf öğrencilerinin, kavram yanılgılarını belirlemek ve yükseklik hakkında sahip olduğu bilgileri öğrenmek amacıyla araştırmacılar tarafından altı bölümden oluşan ve 100 puan değerinde bir başarı testi geliştirilmiştir. Bu testin bölümlerine ait sorular, ilgili alan yazın taranarak ve araştırmacıların deneyimlerinden yararlanılarak belirlenmiştir.

Öğrencilerden; testin birinci bölümünde açık uçlu bir soruyu cevaplandırmaları, ikinci bölümde doğru ya da yanlış olarak verilen sorulardan doğru veya yanlış olma durumlarını gerekçeleri ile açıklamaları, üçüncü bölümde çoktan seçmeli bir soruyu doğru cevaplandırmaları, dördüncü bölümde çeşitli şekillerde konumlanmış halde verilen üçgen ve dörtgenlere ait yükseklikleri çizmeleri, beşinci bölümde çokgenlere ait verilen doğru parçalarından yükseklik olanlarını belirlemeleri, altıncı bölümde ise çokgenlerin herhangi bir kenarı işaretlenerek o kenara ait yükseklikleri çizmeleri istenmiştir. Bölümlere ait puanlar Tablo $1^{\prime}$ de verilmektedir.

Tablo 1. Testteki Soruların Analizinde Kullanılan Değerlendirme

\begin{tabular}{lrrr}
\hline Test & Anlama & Puan \\
\hline \multirow{3}{*}{ 1.Bölüm } & Doğru & 5 \\
& Kısmen doğru & 3 \\
Yanlış & Boş & 0 \\
\hline \multirow{2}{*}{ 2.Bölüm } & Doğru Cevap-Doğru Gerekçe & 2 \\
& & Doğru Cevap-Yanliş Gerekçe & 1 \\
& Yanlış Cevap & 0 \\
\hline
\end{tabular}




\begin{tabular}{crr}
\hline 3.Bölüm & Doğru & 5 \\
\hline & Yanlış & 1 \\
4.Bölüm (Her bir Madde İçin) & Boş & 0 \\
& Doğru & 1 \\
5.Bölüm (Her bir Madde İçin) & Yanlış & 0 \\
& Boş & 0 \\
\hline & Doğru & 1 \\
6.Bölüm (Her bir Madde İçin) & Yanlış & 0 \\
& Boş & 0 \\
\hline
\end{tabular}

$\mathrm{Bu}$ ölçme aracı, alanında uzman iki öğretim elemanı ve iki öğretmen tarafından da incelenerek bu testin, ilköğretim 5. sınıf öğrencilerinin yükseklik kavramı ile ilgili başarılarını ölçmeye yönelik olduğu kabul edilmiştir. YBT her iki okuldaki hem kontrol hem de deney gruplarına ön test- son test olarak uygulanmıştır. Ölçme aracından elde edilen bulgular SPSS 15.0 paket programı kullanılarak çözümlenmiştir.

\section{Uygulama}

Bu çalışma, 2012-2013 eğitim-öğretim yılının Bahar döneminde Ankara ilinin bir devlet ve bir de özel olan iki ortaokulunda öğrenim görmekte olan 80 öğrenci ile yürütülmüştür. Sınıf başarı düzeyleri homojen olan devlet okulundaki sınfflardan biri (5-A) deney grubu $(n=23)$, diğeri (5-B) kontrol grubu $(n=23)$; özel okuldaki sınıflardan biri (5-D) deney grubu $(n=18)$, diğeri (5-A) de kontrol grup $(n=16)$ olarak belirlenmiştir. Kontrol gruplarındaki dersler geleneksel yöntemle Milli Eğitim müfredatı tarafından önerilen şekilde, deney gruplarındaki dersler ise Kavramsal Değişim Metinlerinden yararlanılarak (KDM) işlenmiştir.

KDM hazırlama sürecinde 4 aşama dikkate alınarak dersler düzenlenmiştir. Bu aşamalar yetersizlik, anlaşılabilirlik, mantıklılık ve verimlilik şeklindedir.

Bu sürecin;

Yetersizlik aşamasında: deney grubunda bulunan öğrencilere Yükseklik nedir? sorusu sorulmuş ve öğrencilerin cevaplarını bir kağıda yazmaları istenmiştir. Öğrencilerden alınan cevaplar dikkate alınarak onların sahip olduğu mevcut kavram yanılgıları belirlenmiş ve ardından öğrencilere yanlış kavramlardan oluşan bir metin verilmiştir. Böylece öğrencilerin, yanlış kavramlar üzerinde tartışmalarına olanak verilerek sahip oldukları kavram yanılgılarını kendilerinin tespit etmeleri sağlanmıştır.

Anlaşılabilirlik aşamasında: öğrencilere Yükseklik kavramı ile ilgili bilimsel olarak doğru olan ifadeler verilmiş, böylece doğru olan ifadelerin onlar tarafından daha iyi kavranılmasına çalışılmıştır.

Mantıkllık aşamasında: öğrencilere yükseklik kavramı ile ilgili problemleri çözebilmelerini sağlayan yeni ifadeler verilmiştir.

Verimlilik aşamasında: öğrencilerin öğrendikleri bilgileri kullanmalarını sağlayabilecek bir metin verilmiş, bu metnin sonuna da öğrencilerin öğrendiklerini değerlendirme amaçlı değerlendirme soruları konulmuştur.

Burada KDM leri, öğrencilerin kavrama yönelik yanlış algılamalarını bilimsel olanlarla değiştirmek, onların yükseklik kavramını daha iyi anlayabilmelerini ve onlarda kalıcı öğrenmeyi sağlamak amacı ile hazırlanmıştır. Hazırlanan bu KDM için uzman görüşü alınarak kullanıma uygun olduğu belirlenmiştir.

Devlet okulunun deney ve kontrol gruplarında uygulama, A araştırmacısı, özel okuldaki deney ve kontrol gruplarındaki uygulama ise $\mathrm{B}$ araştırmacısı tarafından yürütülmüştür. 


\section{Bulgular ve Yorum}

\section{1) Devlet Okulundaki Öğrencilere ait Bulgular}

a) Birinci alt probleme ilişkin bulgular ve yorum: Çalışmanın deney (5-A) ve kontrol grubunda (5-B) yer alan öğrencilerin ön test başarı puanları, ilişkisiz örneklemler t-testi ile karşılaştırılarak elde edilen sonuçlar Tablo 2' de verilmektedir.

Tablo 2. Deney ve Kontrol Gruplarının Ön Test Puanlarının Karşılaştırılması

\begin{tabular}{rcccccc}
\hline Gruplar & $\mathbf{N}$ & $\overline{\boldsymbol{X}}$ & $\mathbf{S s}$ & $\mathbf{S d}$ & $\mathbf{t}$ & $\mathbf{p}$ \\
\hline Deney & 23 & 59.08 & 9.816 & 44 & -.729 & .232 \\
Kontrol & 23 & 61.43 & 11.93 & & & \\
\hline
\end{tabular}

Tablo 2' de görüldüğü gibi, deney grubunun başarı ortalaması $(\bar{X}=59.08$, Ss $=9.816)$, kontrol grubunun başarı ortalamasından $(\bar{X}=61.43, \mathrm{Ss}=11.93)$ farklıdır. Ancak bu fark anlamlı değildir, $\mathrm{t}(44)=-.729, \mathrm{p}>.05$. Bu bulgu, deney ve kontrol gruplarındaki öğrencilerin öğretim öncesi konu ile ilgili ön bilgilerinin denk olduğunu ve başarı yönünden aralarında anlamlı bir fark olmadı̆̆ını göstermektedir.

b) İkinci alt probleme ilişkin bulgular ve yorum: Çalışmanın deney (5-A) grubunda yer alan öğrencilerin ön test ve son test başarı puanları ilişkili örneklemler t-testi ile karşılaştırılarak elde edilen sonuçlar Tablo 3'te verilmektedir.

Tablo 3. Deney Grubundaki Öğrencilerin Ön Test ve Son Test Puanlarının Karşılaştırılması

\begin{tabular}{rlccccc}
\hline Gruplar & $\mathbf{N}$ & $\overline{\boldsymbol{X}}$ & Ss & Sd & $\mathbf{t}$ & $\mathbf{p}$ \\
\hline Ön Test & 23 & 59.087 & 9.81 & 22 & -13.415 & .00 \\
Son Test & 23 & 81.304 & 9.41 & & & \\
\hline
\end{tabular}

Tablo 3' te görüldüğü gibi, 5. sınıfta öğrenim gören deney grubu öğrencilerinin Kavramsal Değişim Metinleri (KDM) ile yapılan ders sonrası başarı testinden aldıkları puan ortalaması $(\bar{X}=81.304$, Ss $=9.41)$ bu etkinlik yapılmadan önceki başarı testinden aldıkları puan ortalamasından $(\bar{X}=59.087$, Ss $=9.81)$ daha yüksektir. Bu artış anlamlı bir fark oluşturmaktadır, $\mathrm{t}(22)=-13.415, \mathrm{p}<.05$. Yükseklik kavramının KDM yardımıyla öğretilmesi öğrencilerin başarısında anlamlı olacak şekilde bir artış sağlamıştır. Bu bulguya dayanılarak KDM ile yapılan öğretimin öğrenci başarısını artırdı̆̆ı söylenebilir.

c) Üçüncü alt probleme ilişkin bulgular ve yorum: Kontrol grubunda (5-B) yer alan öğrencilerin ön test ve son test başarı puanları da ilişkili örneklemler t-testi ile karşılaştırılarak ve elde edilen sonuçlar Tablo $4^{\prime}$ te verilmektedir.

Tablo 4. Kontrol Grubu Öğrencilerinin Ön Test ve Son Test Puanlarının Karşılaştırılması

\begin{tabular}{ccccccc}
\hline Gruplar & $\mathbf{N}$ & $\overline{\boldsymbol{X}}$ & $\mathbf{S s}$ & $\mathbf{S d}$ & $\mathbf{t}$ & $\mathbf{p}$ \\
\hline Ön Test & 23 & 61.43 & 11.93 & 22 & -.857 & .401 \\
Son Test & 23 & 64.52 & 14.57 & & & \\
\hline
\end{tabular}

Tablo 4' te görüldüğü gibi, 5. sınıfta öğrenim gören öğrencilerin geleneksel anlatım yolu ile yapılan öğretim sonrası başarı testinden aldıkları puan ortalaması $(\bar{X}=64.52$, Ss $=14.57)$, konu anlatımı olmadan önceki başarı testinden aldıkları puan ortalamasından $(\bar{X}=61.43$, Ss $=11.93)$ daha yüksektir. Bu artış anlamlı bir fark oluşturmamaktadır, $\mathrm{t}(22)=-.857, \mathrm{p}>.05$. Bu bulgu, kontrol grubunda uygulanan geleneksel öğretim yönteminin öğrenci başarısında anlamlı bir değişiklik oluşturmadığını göstermektedir. 
d) Dördüncü alt probleme ilişkin bulgular ve yorum: Deney ve kontrol grubu öğrencilerinin son test başarı puanları ilişkisiz örneklemler t-testi ile karşılaştırılarak elde edilen sonuçlar Tablo 5 'te verilmektedir.

Tablo 5. Deney ve Kontrol Gruplarının Son Test Puanlarının Karşılaştırılması

\begin{tabular}{rcccccc}
\hline Gruplar & $\mathbf{N}$ & $\overline{\boldsymbol{X}}$ & $\mathbf{S s}$ & $\mathbf{S d}$ & $\mathbf{t}$ & $\mathbf{p}$ \\
\hline Deney & 23 & 81.91 & 9.095 & 44 & 4.854 & .00 \\
Kontrol & 23 & 64.52 & 14.578 & & & \\
\hline
\end{tabular}

Tablo $5^{\prime}$ te görüldüğü gibi deney grubunda yer alan öğrencilerin başarı ortalaması $(\bar{X}=81.91$, Ss $=$ 9.095) kontrol grubundaki öğrencilerin ortalamasından $(\bar{X}=64.52$, Ss $=14.578)$ farklıdır. Bu fark deney grubu lehine anlamlıdır, $\mathrm{t}(44)=4.854, \mathrm{p}<.05$. Bu bulgu, deney grubunda KDM ile yapılan öğretimin, kontrol grubunda yapılan geleneksel öğretime göre öğrenci başarısını artırmada daha etkili olduğunu göstermektedir.

\section{2) Özel Okuldaki Öğrencilere ait Bulgular;}

a) Birinci alt probleme ilişkin bulgular ve yorum: Çalışmanın deney (5-D) ve kontrol grubunda (5-A) yer alan öğrencilerin ön test başarı puanları ilişkisiz örneklemler t-testi ile karşılaştırılarak elde edilen sonuçlar Tablo 6'da verilmektedir.

Tablo 6. Deney ve Kontrol Gruplarının Ön Test Puanlarının Karşılaştırılması

\begin{tabular}{ccccccc}
\hline Gruplar & $\mathbf{N}$ & $\overline{\boldsymbol{X}}$ & Ss & Sd & $\mathbf{t}$ & $\mathbf{p}$ \\
\hline Deney & 18 & 69.55 & 11.29 & 33 & .567 & .574 \\
Kontrol & 17 & 67.41 & 11.03 & & & \\
\hline
\end{tabular}

Tablo $6^{\prime}$ da görüldüğü gibi, deney grubunun başarı ortalaması $(\bar{X}=69.55$, Ss $=11.29)$, kontrol grubunun başarı ortalamasından $(\bar{X}=67.41$, Ss $=11.03)$ farklıdır. Ancak bu fark anlamlı değildir, $\mathrm{t}(33)=.567, \mathrm{p}>.05$. Bu bulgu, deney ve kontrol gruplarındaki öğrencilerin öğretim öncesi konu ile ilgili ön bilgilerinin denk olduğunu ve başarı yönünden aralarında anlamlı bir fark olmadığını göstermektedir.

b) İkinci alt probleme ilişkin bulgular ve yorum: Çalışmanın deney (5-D) grubunda yer alan öğrencilerin ön test ve son test başarı puanları ilişkili örneklemler t-testi ile karşılaştırılarak elde edilen sonuçlar Tablo7' de verilmektedir.

Tablo 7. Deney Grubundaki Öğrencilerin Ön Test ve Son Test Puanlarının Karşılaştırılması

\begin{tabular}{ccccccc}
\hline Gruplar & $\mathbf{N}$ & $\overline{\boldsymbol{X}}$ & Ss & Sd & $\mathbf{t}$ & $\mathbf{p}$ \\
\hline Ön Test & 18 & 69.352 & 11.61 & 16 & -10.949 & .00 \\
Son Test & 18 & 89.588 & 8.24 & & & \\
\hline
\end{tabular}

Tablo 7' de görüldüğü gibi, 5. sınıfta öğrenim gören deney grubu öğrencilerinin KDM ile yapılan ders sonrası başarı testinden aldıkları puan ortalaması $(\bar{X}=89.588, \mathrm{Ss}=8.24)$ bu etkinlik yapılmadan önceki başarı testinden aldıkları puan ortalamasından $(\bar{X}=69.352$, Ss $=11.61)$ daha yüksektir. Bu artış anlamlı bir fark oluşturmaktadır, $\mathrm{t}(16)=-10.949, \mathrm{p}<.05$. Yükseklik kavramının KDM yardımıyla öğretilmesi öğrencilerin başarılarında anlamlı olacak şekilde bir artış sağlamıştır. Bu bulguya dayanılarak KDM ile yapılan öğretimin öğrenci başarısını arttırdığı söylenebilir.

c) Üçüncü alt probleme ilişkin bulgular ve yorum: Kontrol grubunda (5-A) yer alan öğrencilerin ön test ve son test başarı puanları da ilişkili örneklemler t-testi ile karşılaştırılarak ve elde edilen sonuçlar Tablo 8 ' de verilmektedir. 
Tablo 8. Kontrol Grubu Öğrencilerinin Ön Test ve Son Test Puanlarının Karşılaştırılması

\begin{tabular}{ccccccc}
\hline Gruplar & $\mathbf{N}$ & $\overline{\boldsymbol{X}}$ & Ss & Sd & $\mathbf{t}$ & $\mathbf{p}$ \\
\hline Ön Test & 17 & 67.41 & 11.03 & 16 & -.294 & .772 \\
Son Test & 17 & 68.00 & 9.99 & & & \\
\hline
\end{tabular}

Tablo 8' de görüldüğü gibi, 5. sınıfta öğrenim gören öğrencilerin geleneksel anlatım yolu ile yapılan öğretim sonrası başarı testinden aldıkları puan ortalaması $(\bar{X}=68.00$, Ss $=9.99)$, konu anlatımı olmadan önceki başarı testinden aldıkları puan ortalamasından $(\bar{X}=67.41$, Ss $=11.03)$ daha yüksektir. Bu artış anlamlı bir fark oluşturmamaktadır, $\mathrm{t}(16)=-.294, \mathrm{p}>.05$. Bu bulgu, kontrol grubunda uygulanan geleneksel öğretim yönteminin öğrenci başarısında anlamlı bir değişiklik oluşturmadığını göstermektedir.

d) Dördüncü alt probleme ilişkin bulgular ve yorum: Deney ve kontrol grubu öğrencilerinin son test başarı puanları ilişkisiz örneklemler t-testi ile karşılaştırılarak elde edilen sonuçlar Tablo 9' da verilmektedir.

Tablo 9. Deney ve Kontrol Gruplarının Son Test Puanlarının Karşılaştırılması

\begin{tabular}{rcccccc}
\hline Gruplar & $\mathbf{N}$ & $\overline{\boldsymbol{X}}$ & Ss & Sd & $\mathbf{t}$ & $\mathbf{p}$ \\
\hline Deney & 18 & 90.16 & 8.368 & 33 & 7.130 & .00 \\
Kontrol & 17 & 68.00 & 9.99 & & & \\
\hline
\end{tabular}

Tablo 9' da deney grubunda yer alan öğrencilerin başarı ortalaması $(\bar{X}=90.16$, Ss $=8.368)$ kontrol grubundaki öğrencilerin ortalamasından $(\bar{X}=68.00, \mathrm{Ss}=9.99)$ farklıdır. Bu fark deney grubu lehine anlamlıdır, $\mathrm{t}(33)=7.130, \mathrm{p}<.05$. Bu bulgu, deney grubunda KDM ile yapılan öğretimin, kontrol grubunda ki geleneksel öğretime göre öğrenci başarısını arttırmada daha etkili olduğunu göstermektedir.

\section{Sonuç ve Tartışma}

Bu çalışmada, ilköğretim 5.sınıfta öğrenim görmekte olan devlet okulu ve özel okul öğrencilerinin "yükseklik" kavramı konusunda sahip olduğu kavram yanılgılarının tespiti ve konunun daha iyi kavranılmasının sağlanması için KDM kullanılmıştır.

Yapılan çalışma neticesinde, hem devlet okulu hem de özel okulda öğrenim gören öğrenciler için deney ve kontrol gruplarının ön test puanlarının istatistiksel olarak anlamlı bir farklılık göstermediği tespit edilmiştir ( $p>$.05). Buna karşılık her iki okul için ayrı olarak deney ve kontrol gruplarındaki öğrencilerin son test ortalamalarının deney grubu lehine anlamlı bir farklılık gösterdiği belirlenmiştir $(p<.05)$. Ayrıca her iki okul için de ayrı olarak kontrol gruplarının ön test ve son test puanları arasında istatistiksel olarak anlamlı bir farklılık tespit edilmemiştir ( $p>$.05).

Araştırma sonuçlarına göre hem devlet okulu hem de özel okulda KDM ile yürütülen derslere sahip deney gruplarının geleneksel yöntemle yapılan derslere sahip kontrol gruplarından daha başarılı olduğu tespit edilmiştir. Sonuçlar dikkatle incelendiğinde, $\mathrm{KDM}^{\prime}$ nin kavram öğretiminde kullanılması üzerine yapılan diğer çalışmalarla (Wang ve Andre, 1991; Chambers ve Andre, 1997; Sungur, Tekkaya ve Geban, 2001; Pınarbaşı ve Canpolat, 2002) benzer sonuçlar verdiği görülmektedir.

Günlük hayatta sıklıkla karşımıza çıkan, hayatın yadsınamaz gerçeklerinden matematik bilimi ve onun alt dalı olan geometrinin temelinde pek çok bilgi ve kavram yatmaktadır. Bireylerde anlamlı öğrenme oluşturulması için bu bilgi ve kavramların birbiriyle ilişkilendirilerek iyi bir şekilde kavratılması gerekmektedir. KDM de öğrencilerin zihinlerinde matematik bilgisinin anlamlı olarak yapılandırılmasına katkı sağlayacağından oldukça önemlidir.

Öğrenme, içerisinde birçok yöntem ve teknik barındıran kapsamlı bir süreçtir. Bu süreçte önemli olan, öğretim yöntem ve tekniklerinin doğru yerde doğru zamanda kullanılmasıdır. Çalışmamızda ve benzer birçok çalışmada görüldüğü üzere; geleneksel yöntemlerin öğrenci başarısını istenen yüksek düzeylere 
çıkarmadığı gerçeğiyle karşılaşıyoruz. Bu yüzden, amaçlanan azami başarıya ulaşma yolunda öğrencilere bilgi ve kavramları keşfettirip kendi zihinlerinde kendilerinin yapılandırdığı bir öğrenme ortamı hazırlanmalı ve öğretmenin liderlik rolü, yol gösterici-rehber rolüyle yer değiştirmelidir. KDM de bu sürece yardımcı olabilecek bir yöntem olarak düşünülebilir.

\section{Kaynakça}

Akbaş, Y. \& Uzunöz, A. (2011). Kavramsal değişim yaklaşımına dayalı coğrafya öğretimi: Bir uygulama örneği. E-Journal of New World Sciences Academy,6(2).

Altun, M. (2010). Illköğretim ikinci kademede (6, 7 ve 8. sinıflarda) matematik öğretimi (7. Baskı). Bursa: Alfa.

Alvermann, D. E. \& Hague, S. A. (1989). Comprehension of counter intuitive science text: Effects of prior knowledge and text structure. Journal of Educational Research, 82, 197-202.

Chambers. S. K. \& Andre, T. (1997). Gender prior knowledge, interest and experience and conceptual change text manipulations in learning about direct current?. Journal of Research in Scienee Teaching, $34(2), 107-23$.

Guzzetti, B. J., Snyder, T. E. \& Glass, G. V. (1992). Promoting conceptual change in science: Can texts be used effectively?, Journal of Reading, 35(8), 642-649.

Hewson, P. W. \& Hewson, M. G. (1984). The role of conceptual conflict in conceptual change and the design of science instruction. Instructional Science, 13, 1-13.

Ivie, S. D. (1998). Ausubel' s learning theory: An approach to teaching higher order thinking skills. (Educational psychologist David Paul Ausubel). High School Journal, 35(1).

Köseoğlu, F. \& Kavak, N. (2001). Fen öğretiminde yapılandırıcı yaklaşım. Gazi Eğitim Fakültesi Dergisi, 21(1), $138-148$.

Pınarbaşı, T. \& Canpolat, N. (2002). Fen eğitiminde kavramsal değişim yaklaşımı-II: Kavram değiştirme metinleri. Kastamonu Ĕ̆itim Dergisi, 10(2), 281-286.

Posner, G. J., Strike, K. A., Hewson, P. W., \& Gertzog, W. A. (1982). Accommodation of a scientific conception: Toward a theory of conceptual change. Science Education, 66, 211-227.

Sungur, S., Tekkaya, C. \& Geban, Ö. (2001). The contribution of conceptual change texts accompanied by concept mapping to students' understanding of the human circulatory system. School Science and Mathematics, 101(2), 91-101.

Van de Walle, J. A. (1998). Elementary and middle school mathematics: Teaching developmentally (3rd ed.). New York: Longman.

Wang, T. \& Andre, T. (1991). Conceptual change text versus traditional text and application questions versus no questions in learning about electricity. Contemporary Educational Psychology, 16(2), 103-116.

Yenilmez, K. \& Yaşa, E. (2008). İlköğretim öğrencilerinin geometrideki kavram yanılgıları. Eğitim Fakültesi Dergisi, 21(2), 461-483. 